\title{
Exploratory science learning in a high school curriculum, using structured materials and light polarization
}

Yasuyo Suzuki, Nathan Hagen, Yukitoshi Otani

Yasuyo Suzuki, Nathan Hagen, Yukitoshi Otani, "Exploratory science learning in a high school curriculum, using structured materials and light polarization," Proc. SPIE 11143, Fifteenth Conference on Education and Training in Optics and Photonics: ETOP 2019, 111432L (2 July 2019); doi: 10.1117/12.2523719 Photonics: ETOP 2019, 2019, Quebec City, Quebec, Canada 


\title{
Exploratory science learning in a high school curriculum, using structured materials and light polarization
}

\author{
Yasuyo Suzuki*a , Nathan Hagen ${ }^{\mathrm{b}}$, Yukitoshi Otani ${ }^{\mathrm{b}}$ \\ a'Utsunomiya Girls' high school, 5-19 Misaocho, Utsunomiya, Tochigi, JAPAN 320-0963 \\ ${ }^{b}$ Dept. of Optical Engineering Center for Optical Research and Education (CORE) \\ Utsunomiya University, 7-1-2 Yoto, Utsunomiya, Tochigi, JAPAN 321-8585
}

\begin{abstract}
Utsunomiya Girls' High School has participated in the national "Super Science High School" science education program for ten years. The program aims to improve advanced science education in high school and to let advanced high school students experience open scientific inquiry, through collaboration with researchers at Utsunomiya University. Our group of students is currently involved in studying the structural color of insects - a topic that brings together chemistry, biology, and optics. Therefore, even students who do not study physics are exposed to interesting optical phenomena. It is well known that beetles' shells exhibit circular polarization, but among similar insects, one will show circular polarization while others do not. Our initial investigation involved imaging the shells of several beetles with an imaging Stokes polarimeter and an electron microscope. As a result, we were able to observe the structural differences between the two types of insects. Next, we tried to experimentally reproduce the same structures using a cholesteric liquid crystal having properties similar to the beetle shells. This provides a means of not just observing but also experimentally investigating structural color of insects.
\end{abstract}

Keywords: optics, high school science, polarization, liquid crystal

\section{INTRODUCTION}

While the importance of advanced science education in high schools is recognized in Japan, it can be difficult to introduce advanced topics in the usual curriculum. Thus, for the past 10 years the Utsunomiya Girls' High School has adapted the Japanese national Super Science High School (SSH) Program as a complement to its regular science curriculum. About 200 schools nationwide currently participate in the program, which has been supported for 17 years by the Ministry of Education, Culture, Sports, Science and Technology of Japan. The goal of the program is to provide students with the ability to explore phenomena through developmental learning, and participating students have demonstrated improvements in autonomy, creativity, and problem solving skills. In our high school curriculum, all freshman students take basic physical science classes - mechanics, thermodynamics, waves, and electromagnetism. In their second and third year, students who are thinking about going on to science, engineering, medicine, and pharmacy careers (about $30 \%$ of the student body) go on to take more advanced physical science courses. However, even these science-oriented students are given little exposure to optics subjects, which is the field of study our group decided to focus on. The total number of textbook pages in the three-year high school physics curriculum is 646 pages. Table 1 gives the portion of space devoted to each field, in which we see that the number of pages devoted to mechanics is the largest at 30\%, while that of optics is the least at only $5 \%$. As a result of this focus on mechanics and electromagnetism, it is difficult for students to achieve a good understanding about polarization and other optical properties. Thus, optics research under the SSH program can be considered as an approach to increasing optical science content. 
Table 1. Number of pages in each field covered in Japanese high school textbooks.

\begin{tabular}{|lcc|}
\hline \multicolumn{3}{|c|}{ High school physics textbooks in Japan } \\
Field & Number of pages & Percentage \\
\hline Mechanics & 197 & $30.5 \%$ \\
Electromagnetism & 160 & $24.8 \%$ \\
Atomic \& Nuclear Physics & 86 & $13.3 \%$ \\
Waves & 77 & $11.9 \%$ \\
Thermodynamics & 54 & $8.4 \%$ \\
Optics & 35 & $5.4 \%$ \\
Total number of pages & 646 & $100 \%$ \\
\hline
\end{tabular}

\section{OUR APPROACH TO THE SSH PROGRAM}

There are about 840 students in Utsunomiya Girls' High School, of which about 40 second grade students participate in the research activities that are central to the SSH program. Several students are grouped together to work on a single theme, and visit Utsunomiya University regularly about 10 times a year to conduct research while receiving advice from university faculty. In addition to this, our program includes activities such as lectures from invited researchers, visits to research facilities and nearby companies, etc. In the specific theme we discuss here, two different groups of students conducted research over a period of two years on the theme of the structural color of insects. Rather than the ecology and anatomy of each insect, students focused on learning about the creatures from the standpoint of trying to develop new materials by mimicking them. Because the theme brings together elements not just from optics but also from mechanics, chemistry, and biology, it is an attractive subject to bring together our students' understanding of science.

\section{OUTLINE OF RESEARCH}

Research on the circular polarization of scarab beetles' carapaces began when Albert Michelson first viewed scarab beetles through circular polarizers in 1911. Since then, it has become widely known that certain types of beetles produce such polarization structure in reflection. If the outermost surface of a scarab beetle's shell is peeled off and viewed in transmission, one observes that linearly polarized light is rotated by the material. Thus, the circular diattenuation effect produced by the shell is produced by the layered structure forming the surface of the pronotum and elytra (head and wings). This structure is now known to closely resemble that of a cholesteric liquid crystal.
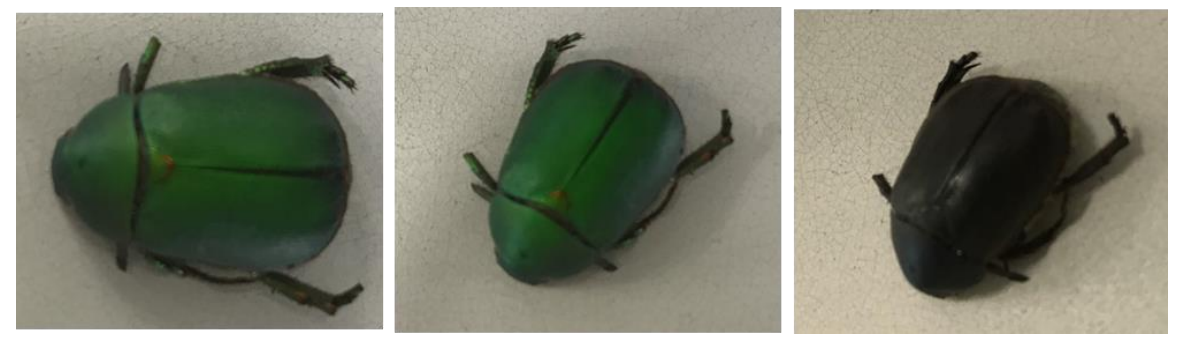

Figure 1. The scarab beetle (Anomala albopilosa) under study. The picture on the left is a beetle illuminated with natural light. The center photo was taken while viewing the beetle through a right circular polarizer, and the right photo while viewing through a left circular polarizer. The beetle turns black in the rightmost figure because its carapace does not reflect right circularly polarized light.

Cholesteric liquid crystals are characterized by a state in which nematic liquid crystal molecules are aligned in one direction, and gradually change their orientation to form a helical structure (Fig. 2). 


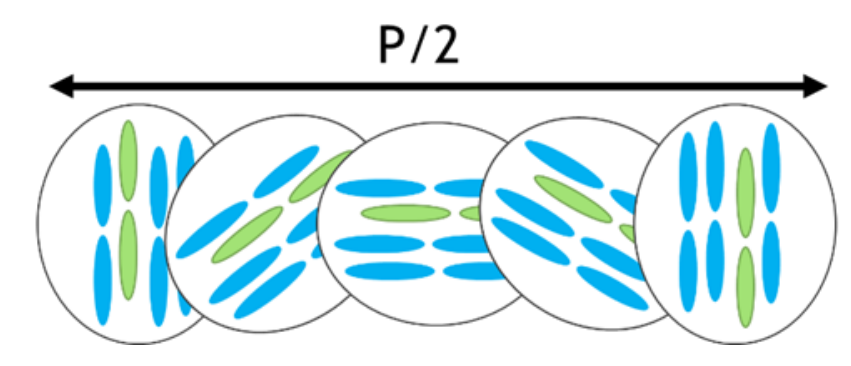

Figure 2. Schematic of a cholesteric liquid crystal. Cholesteric liquid crystals are formed by linearly oriented nematic liquid crystals whose orientation rotates along the depth direction to form a helical structure.

It is known that filamentous molecules called micro fibrils are arranged linearly within the epidermis of insects, and they can rotate in orientation from one layer of micro fibrils to the next below it. When light enters such a helical layer, it acquires a different phase upon propagation if polarized in the same or the opposite sense as the structural helix. Assuming that the pitch of the phase delay induced by passing through the helical structure is $P$ (Fig. 2), light of a wavelength proportional to $P$ / 2 gains a high reflectivity. If the phase delay of light polarized in the opposite sense is proportional to $P / 4$, then it acquires a low reflectivity, in the same way that a quarter-wave coating can be used to form the anti-reflection coating on lenses. Among world fauna, only the beetles have shown such structures, and it is not yet known what kind of benefit the polarized reflection brings.

\section{IMAGING POLARIMETRY OF BEETLES}

The degree of polarization was measured using the Stokes imaging polarimeter shown in Fig. 3. In this apparatus, a halogen light source is used to irradiate the sample with light passing through a narrow-band spectral filter, a linear polarizer, and a broadband achromatic quarter-wave plate. The reflected light is imaged by a camera through a rotating quarter-wave plate and linear polarizer.

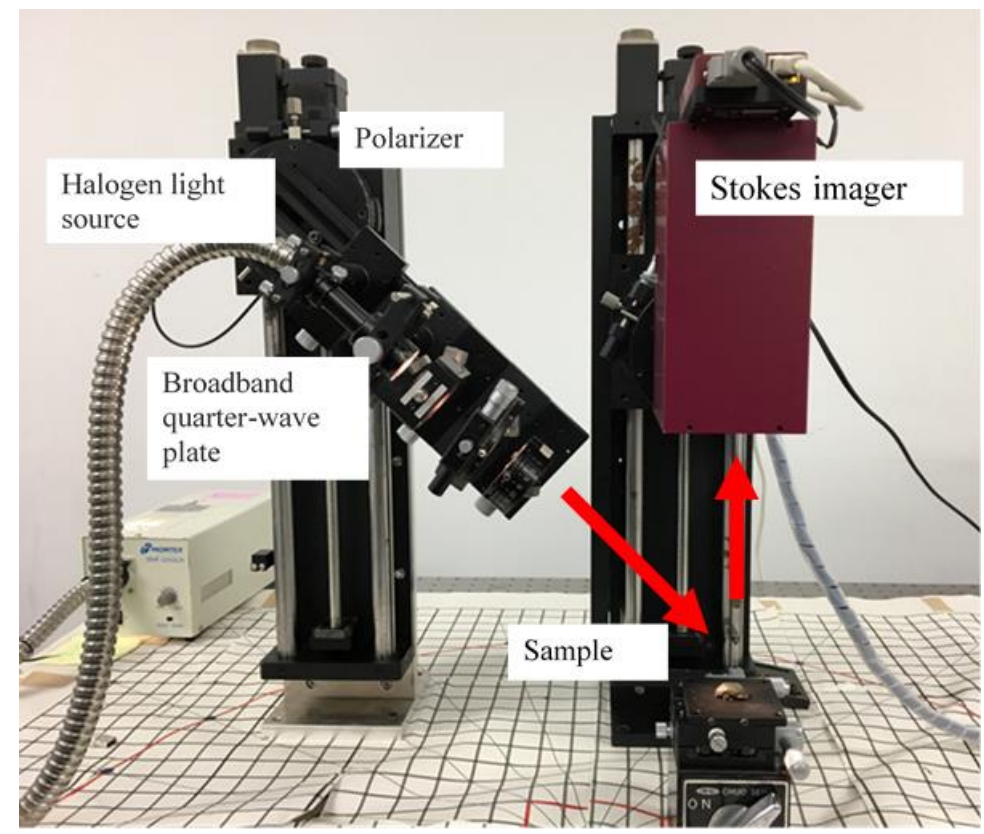

Figure 3. At left, light emitted from a halogen light source is passed through a narrowband spectral filter, a linear polarizer, and a broadband achromatic quarter-wave plate to illuminate the sample. At the upper right, the reflected light from the sample imaged by a Stokes imager using a rotating broadband achromatic quarter-wave plate and linear polarizer. 
Figures 4 and 5 show the measured circular polarization component (normalized Stokes parameter $s_{3}$ ) reflected from the shell of A. albopilosa and Phelotrupes laevistriatus from $450 \mathrm{~nm}$ to $650 \mathrm{~nm}$. In English, A. albopilosa is known as a "shining leaf chafer" and in Japanese as "Aodougane". P. laevistriatus is known in English as a "dung beetle", and in Japanese as "senchikogane". Both beetles belong to the family Scarabaeidae. Whereas A. albopilosa shows strong circular polarization in reflection, $P$. laevistriatus shows only small polarization signature. The blue areas shown in the $A$. albopilosa images at $450 \mathrm{~nm}$ and $500 \mathrm{~nm}$ are likely specular reflection artifacts induced by saturation. Likewise, the blue areas shown at all of the measured wavelengths in the P. laevistriatus images are probably also saturation artifacts. The dark color of $P$. laevistriatus shiny shell makes for a difficult measurement that requires handling data over a wide dynamic range. Both of these insects are often found in Japan and can easily be collected at school.

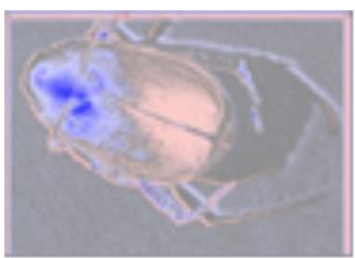

$450 \mathrm{~nm}$

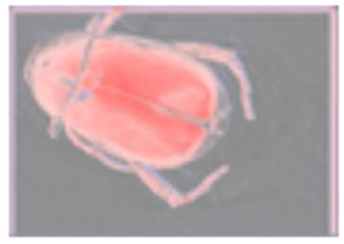

$600 \mathrm{~nm}$

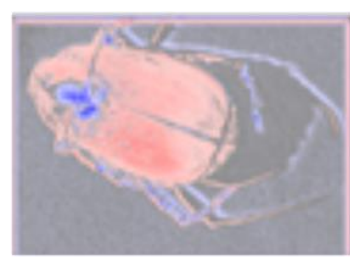

$500 \mathrm{~nm}$

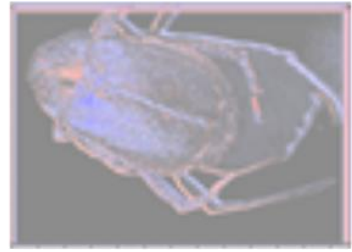

$650 \mathrm{~nm}$

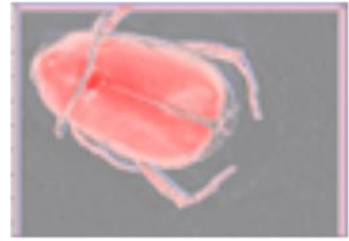

\section{$550 \mathrm{~nm}$}

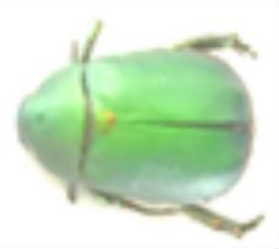

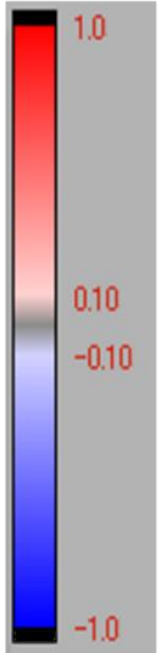

right circular polarization

left

circular polarization

Figure 4. A. albopilosa (common name: shining leaf chafer; in Japanese, aodogane) measured with a Stokes imaging polarimeter. The generally red appearance indicates that the beetle's shell reflects primarily right-circularly polarized light.

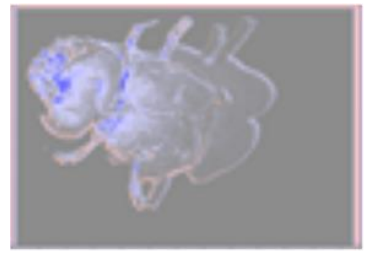

$450 \mathrm{~nm}$

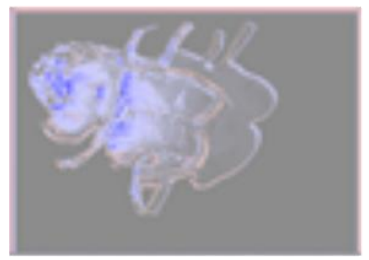

$600 \mathrm{~nm}$

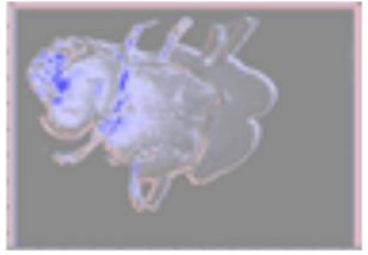

$500 \mathrm{~nm}$

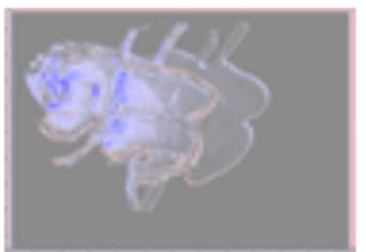

$650 \mathrm{~nm}$
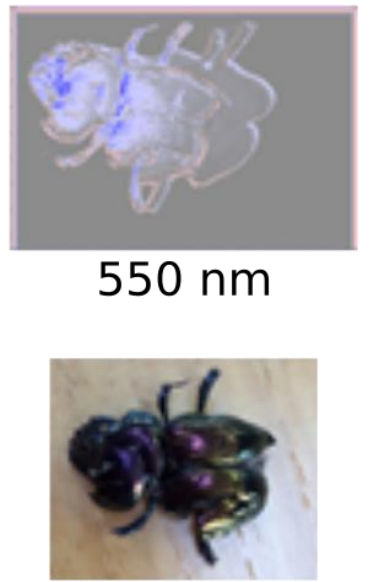

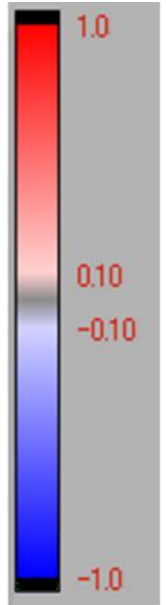

left circular polarization

Figure 5. It is the result of measuring P. laevistriatus (common name: dung beetle; in Japanese, senchikogane) with a Stokes polarimeter. The darker red is closer to the right circularly polarized light, and the darker blue is closer to the left circularly polarized light. 
A. albopilosa is treated as a pest that damages agricultural crops because as a larva it eats the roots of underground plants, and as an adult it eats the leaves of broadleaf trees. P. laevistriatus, on the other hand, feeds on mushroom and so is not considered a pest. In order to investigate the cause of the difference in the polarization measurements, we examined a cross section of the wing epidermis with an electron microscope (Fig. 6). Whereas A. albopilosa has fibers with different orientations overlapping in layers, $P$. laevistriatus has fiber layers that are aligned to one another.
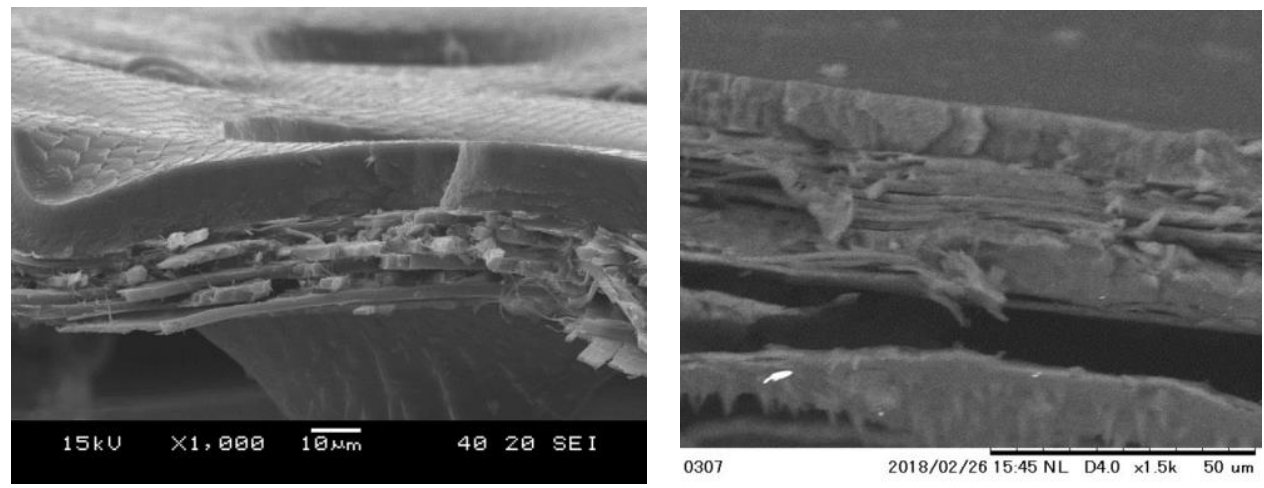

Figure 6. Electron micrograph of the cross section of the beetle wing epithelium, (left) A. albopilosa, (right) P. laevistriatus.

In addition to measuring the optical properties of the beetles, we also conducted an experiment on the question of whether insects having epithelial polarization can see and respond to polarized light. The relationship between the type of light irradiated and the behavior of the insects was investigated for the Protaetia orientalis ("Asian flower beetle"; or shiroten hanamuguri in Japanese), which belongs to another family close to A. albopilosa, and is also a member of Scarabidae. However, trying to determine whether the beetles' behavior changes depending on the polarization of illumination gave inconclusive results, so we next tried to observe the structure of $P$. orientalis' eye. While it has been reported that Scarabidae family possesses a compound eye (Gokan 1992), when the compound eye was imaged under an electron microscope (Fig. 7 left), the appearance is that of a monolithic eye. The reason for the difference is that $P$. orientalis has a smooth covering that overlays and protects the ommatidia, so that it is not possible to observe the individual ommatidia through this layer using an electron beam. (The ommatidia, however, are easy to see in visible light using a microscope.) This covering layer is not a feature found in all insect compound eyes, and it is not fully understood why it exists. Therefore, when observed with a stereomicroscope, compound eyes could be observed as shown in the center of Fig. 7.
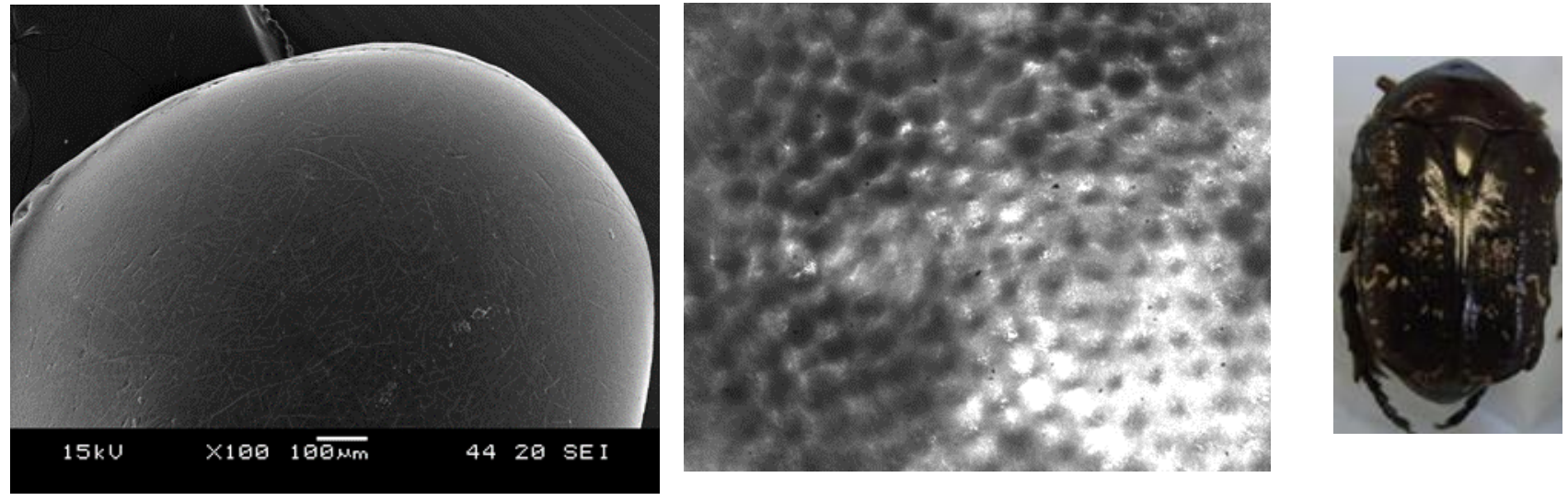

Figure 7. (Left) Electron micrograph of a $P$. orientalis eye; (Center) a zoomed-in view of a portion of the eye through a stereomicroscope; (Right) a color image of $P$. orientalis taken with a camera. 
Finally, we also studied how to replicate the structure that produces circular diattenuation in reflected light from the beetles' shells. Since the structure is similar to that of a cholesteric liquid crystal, we tried to make cholesteric liquid crystals and confirm their optical properties. The chemicals used are inexpensive: Hydroxypropyl cellulose (HPC), acetic anhydride, and acetic acid. We mix $10 \mathrm{~g}$ of HPC, $50 \mathrm{ml}$ of acetic anhydride, and $5 \mathrm{ml}$ of acetic acid, then allow the mixture to react while held at $50^{\circ} \mathrm{C}$ for 3 days (Yamagishi 2010). The resulting material (Fig. 8) was then dried on glass preparation slides and the polarization characteristics were measured with a polarimeter.
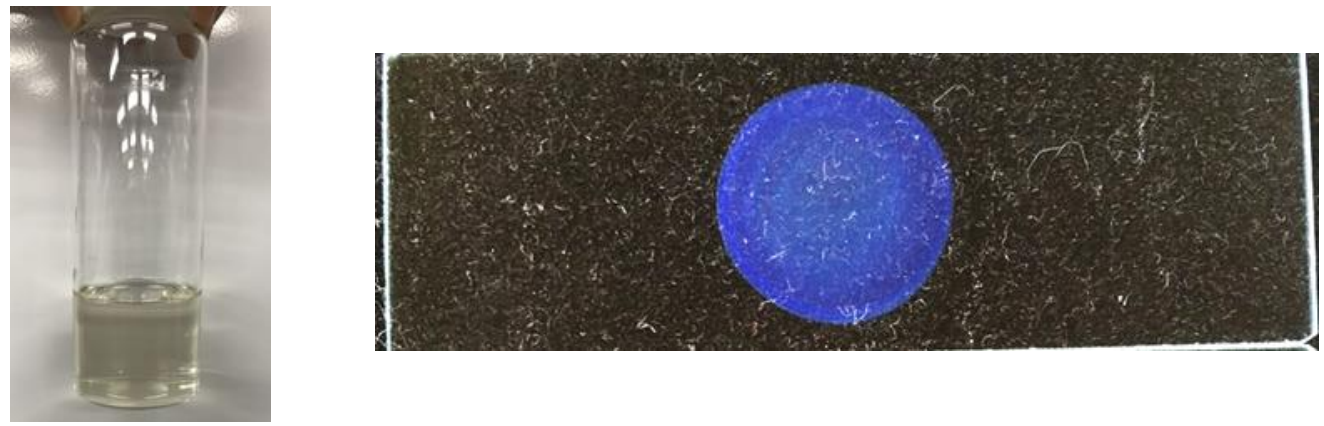

Figure 8. (Left) The translucent yellow liquid mixture used to create the liquid crystal sample; (Right) the dried sample on a glass preparation slide. When viewed in white ambient light, against a dark background (black felt was used here), we can see blue color in reflection.
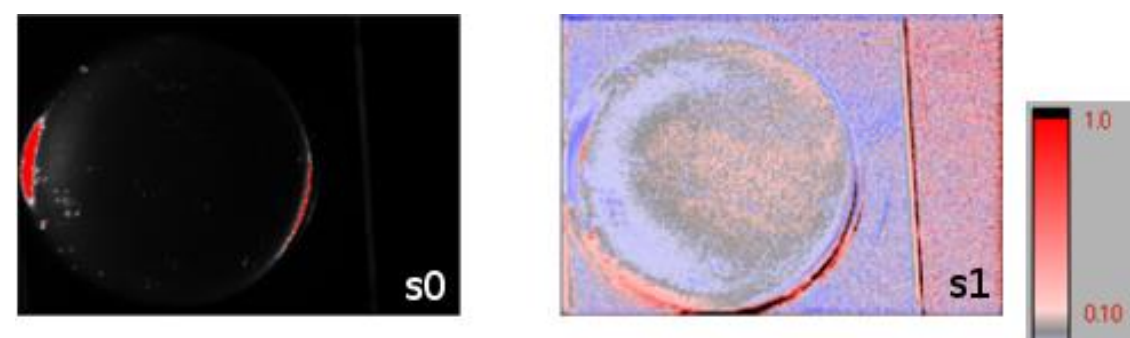

Right circularly

polarized light
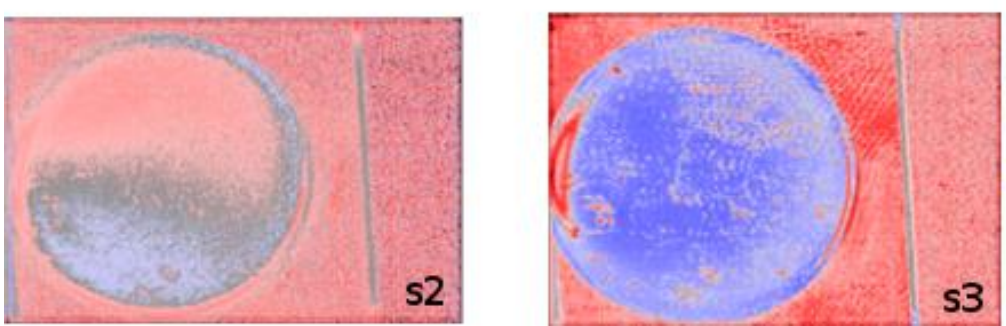

Left circularly polarized light

Figure 9. Results of measurements with a Stokes polarimeter. It can be seen that the sample shows left circularly polarized light. The lower right picture shows circularly polarized light. The dark blue color indicates that the sample exhibits left circularly polarized light.

\section{CONCLUDING REMARKS}

In our implementation of the SSH project at Utsunomiya Girls' High School, the students engaged in a wide-ranging exploratory activity, based on investigating the polarization-generating structures of insect bodies. During their work on this theme, the students could gain a feel for scientific research and how to utilize various measurement methods in order to understand physical phenomena. While pursuing their investigations, the students were much more actively involved in the learning process than is typical for lecture-based high school science classes. One after another question came up in their discussions as they worked to understand the measurements. This is not something that can be experienced in a regular curriculum, and is the result of carrying out exploratory activities with the cooperation of the university. 


\section{ACKNOWLEDGEMENTS}

The authors gratefully acknowledge support from Super Science High School great member, Takashi Kurihara of Tochigi Prefectural museum, Associate Professor Marenori Kawamura of Akita University, Shuhei Shibata of Utsunomiya University.

\section{REFERENCES}

[1] Mitsuo Matsuka, Masao Ono, Hideo Kitano, Nobuo Gokan, and Tadao Matsumoto, [Insect Biology], Tamagawa University Press, Tokyo, 91-93, (1992). [松香光夫, 大野正男, 北野日出男, 後閑暢夫, 松本忠 夫, 昆虫の生物学, in Japanese]

[2] Tadaaki Yamagishi, Akihiko Ishizaki, Yuki Ogose, Yoshiaki Nakamoto, and Akihiko Takada, "Control of the aggregation state of crystalline cellulose derivatives,” Kobunshi Ronbunshu 67:705-708 (2010). [山岸忠明，石 崎昭彦, 生越友樹, 中本義章, 高田晃彦, 結晶性セルロース誘導体の凝集状態制御について, 高分子論 文集, in Japanese]

[3] Shuichi Kinoshita, [Biology Nanophotonics], Asakura Shoten, Tokyo, 111-118, (2010) [木下修一, 生物ナ) フォトニクス, in Japanese] 